\title{
Phenol Adsorption onto Various Soil Composite Membranes: Insight into Process Kinetics, Modelling and Optimisation Using Response Surface Methodology
}

\author{
Papita Das $^{1 *}$, Sudipto Goswami ${ }^{1}$, Priya Banerjee ${ }^{2}$ and Siddhartha Datta ${ }^{1}$ \\ ${ }^{1}$ Department of Chemical Engineering, Jadavpur University, 188, Raja S.C. Mullick Road, Kolkata-700 032, India \\ ${ }^{2}$ Department of Environmental Science, University of Calcutta, 35 Ballygunge Circular Road, Kolkata-700 019, India
}

\begin{abstract}
The present study investigates the potential of soil and soil composites for removal of phenol from solution on a comparative scale. Different experimental parameters were optimized with a novel approach of response surface methodology (RSM) and a central composite design (CCD) for achieving maximum efficiency. Maximum adsorption efficiency $\left(1.44 \mathrm{mg} \mathrm{g}^{-1}\right)$ was obtained at initial $\mathrm{pH} 5.5$, an adsorbent dosage of $7.5 \mathrm{~g} \mathrm{~L}^{-1}$ and a treatment time of 32.5 mins at a temperature of $313 \mathrm{~K}$ as predicted by the RSM design. The phenomenon best fitted the Temkin isotherm at different temperatures. The process was guided by the pseudo-secondorder kinetic model and was analyzed to be spontaneous, endothermic and chemisorption in nature. Characterization of soil particles using Scanning Electron Microscopy and Fourier Transform Infrared Spectroscopy showed the changes in its structure and surface morphology both before and after use and explained it's prospective as a good and environmentally benign adsorbent in very low quantities. Hence, this adsorbent can be implemented as an efficient liner material for the removal of phenol and phenolic compounds from wastewater.
\end{abstract}

Keywords: Adsorption; Soil composites; Liner materials, Phenol; Kinetics; RSM

\section{Introduction}

Phenol is an organic compound of immense environmental concern due to its wide application in petrochemical, oil refining, plastic, leather pharmaceutical and pesticide industries [1-4]. Water contaminated with phenolic compounds possess both unpleasant odour and flavour and is poisonous to flora and fauna even in low concentrations $\left(5 \mu \mathrm{g} \mathrm{L}^{-1}\right)$ [5] and is thereby considered as a major water pollutant $[6,7]$. As per World Health Organisation (WHO) norms, the maximum permissible concentration of phenol in potable water should not exceed $1 \mathrm{mg} \mathrm{L}^{-1}$ [5]. Therefore it has become imperative to treat wastewater for phenol removal prior to its reuse or discharge into the environment.

Phenolic compounds have been previously reported to be degraded by activated sludge but the presence of phenol in wastewaters often leads to increased susceptibility of a biological system to disruption. Hence, several other techniques including chemical oxidation, electro coagulation, solvent extraction, membrane separation and adsorption have been developed for removal of phenol from polluted water $[8,9]$. Recently, adsorption processes have attracted substantial interest due to direct applicability and high sorption capacity obtained in relatively less time. Basically, adsorption is a mass transfer process by which a substance is transferred from the liquid phase to solid phase whereby it becomes bound by the physical and/or chemical interactions. Potentials of various adsorbents like paper mill sludge, coal, dried sewage waste, water hyacinth ash, green macro alga and rice husk ash, etc have been investigated for their ability to remove phenols and phenolic compounds of the various adsorbents reported so far, most are expensive and have low removal efficiency [10-13].

This study was carried out to investigate the potential of clayey soil as a cost effective and efficient adsorbent for treatment of wastewater rich in phenol and phenolic compounds. Clays are distinguished from the other particles present in the soil (such as slit, sand, etc.) by the difference in size and mineral content. Clay particles are characterized by their small size, flake or layered shape, highly affinity for water, low porosity and slow diffusive transport. Clay moieties also exhibit plasticity when mixed with water in certain proportion, become hard and firm when dried and is converted into permanent rock like mass on firing. Clay particles bear negative charges and pick up positively charged particles with ease and act as a membrane by preventing the passage of such charged particles [14-16].

The aim of this study was to evaluate the adsorption capacity of clay soil as a potential adsorbent for removal of phenol from its aqueous solution. However, phenol and phenolic compounds present in wastewaters may exert adverse effects on the double diffusion layer of clay particle resulting in an increase in porosity followed by a corresponding decrease in permeability of soil particles [17]. Therefore, another objective of this work was to ascertain if any admixture/ composite materials could improve the efficiency of clay soil as an adsorbent and render it enhanced properties for removal of phenol and phenolic compounds thereby preventing water contamination. These investigations were carried out in two steps: a preliminary batch study (to understand the effect of different experimental factors like, $\mathrm{pH}$, temperature, Agitation speed, etc. on the process of adsorption) followed by a column study (to determine the efficiency of phenol adsorption by different soil composites on a comparative scale). During the batch studies, the experimental factors were optimized for maximum phenol removal using response surface methodology (RSM). RSM is an optimization procedure based on mathematics and statistics and is implemented for estimation of the most advantageous operational parameters as well as the relative significance of each

*Corresponding author: Papita Das, Associate Professor, Department of Chemical Engineering, Jadavpur University, Kolkata, India, Tel: (033)24572696; Fax: (033)24146378; E-mail: papitasaha@gmail.com

Received April 10, 2015; Accepted May 11, 2015; Published May 13, 2015

Citation: Das P, Goswami S, Banerjee P, Datta S (2015) Phenol Adsorption onto Various Soil Composite Membranes: Insight into Process Kinetics, Modelling and Optimisation Using Response Surface Methodology. Hydrol Current Res 6: 203 doi:10.4172/2157-7587.1000203

Copyright: (c) 2015 Das P, et al. This is an open-access article distributed under the terms of the Creative Commons Attribution License, which permits unrestricted use, distribution, and reproduction in any medium, provided the original author and source are credited. 
Citation: Das P, Goswami S, Banerjee P, Datta S (2015) Phenol Adsorption onto Various Soil Composite Membranes: Insight into Process Kinetics, Modelling and Optimisation Using Response Surface Methodology. Hydrol Current Res 6: 203. doi:10.4172/2157-7587.1000203

Page 2 of 10

parameter involved in complex interactions with other such parameters [18-22]. In this study, central composite design (CCD) of RSM was utilized in determining the effects of solution $\mathrm{pH}$, adsorbent dosage and time of contact on phenol removal by various soil composites used as a membrane. Changes in the adsorbent properties (surface morphology, functional groups, etc.) was characterized both pre and post usage. Process kinetics and equilibrium were also studied.

\section{Materials and Methods}

\section{Collection and preparation of adsorbents}

Clayey soil used in this experiment was collected from the banks of river Ganges particularly from north 24 parganas (Naihati). The clayey soil samples was not purified prior to usage. It was initially sun dried for 7 days. The dried soil was crushed and sieved and then stored in sterile and air-tight plastic containers for further use.

For the column study, soil composites (admixtures) were prepared using bentonite, calcium oxide, cement, fly ash and gypsum separately as reported previously [17]. The adsorbent membranes were prepared with soil having with $10 \%$ admixture in case of composites keeping the total bed height at $2 \mathrm{~cm}$.

\section{Preparation of adsorbate solutions}

All chemicals used for this study were of analytical grade purchased from Merck, India. A stock solution of phenol $\left(\mathrm{C}_{6} \mathrm{H}_{5} \mathrm{OH}\right)$ was prepared by dissolving the required amount of phenol in distilled water $(1000$ $\mathrm{mg} \mathrm{L}^{-1}$ ) without $\mathrm{pH}$ adjustment. Working solutions of the desired concentrations were obtained by successive dilutions of stock solution which were stored in volumetric flasks for further use. A standard curve was prepared using phenol solutions of known concentrations. The concentration of phenol in the solutions was determined using 4-AAP (4-amino antipyrin) and potassium ferrocyanide which resulted in the formation of a red colored complex which was further analyzed by a spectrophotometer at $500 \mathrm{~nm}$ [23]. The initial and final concentrations of phenol were ascertained for each experiment from this standard curve.

\section{Batch studies}

For batch adsorption studies, a predetermined amount of adsorbent was added to $100 \mathrm{~mL}$ phenol solution of known concentration taken in $250 \mathrm{~mL}$ Erlenmeyer flask and kept in an incubator shaker (Innova 42, New Brunswick Scientific, Canada). The influence of adsorbent dose (0.1, 0.5, 1.0, 1.5 and $2.0 \mathrm{~g}), \mathrm{pH}$ (3-8), initial adsorbate concentration $\left(10,20,50\right.$ and $\left.100 \mathrm{mg} \mathrm{L}^{-1}\right)$ and temperature $(293,303,308$ and 313 $\mathrm{K})$ were evaluated during the present study. Sample solutions were collected after predefined time intervals and centrifuged at $3600 \mathrm{rpm}$ for $10 \mathrm{~min}$. Supernatants obtained were prior to determination of the residual phenol concentration of these samples were determined using a UV-Vis spectrophotometer (Varian, Australia) After different time intervals, the treated solutions were collected for analyzing the of phenol in the solution and. The residual phenol concentration in the flask was determined as stated before. All the experiments were replicated twice.

\section{Response surface methodology for optimization of adsorption parameters}

Optimization of phenol adsorption by soil was carried out with three independent process variables including time taken for adsorption, initial $\mathrm{pH}$ of the adsorbate solution and adsorbent dosages used. The selected ranges and levels of variables used in this study are presented in Table 1. The response of the system was evaluated in terms of adsorption efficiency of soil $\left(\mathrm{mg} \mathrm{g}^{-1}\right)$. Calculation of the optimal conditions was performed with the quadratic equation given as follows (Equation 1).

$$
Y=\alpha+\sum_{i=1}^{k} \alpha_{1} X_{1}+\sum_{i=1}^{k} \alpha_{11} X_{i}^{2}+\sum_{i=1} \sum_{j=1+1} \alpha_{i j} X_{i} X_{j}+\varepsilon
$$

Where, $Y$ denotes response (i.e. dependent parameter), $\alpha_{0}$ is the constant coefficient, $\alpha_{\mathrm{i}}, \alpha_{\mathrm{ii}}$ and $\alpha_{\mathrm{ij}}$ denote coefficients of linear, quadratic and interaction effect respectively, $\mathrm{x}_{\mathrm{i}}$ and $\mathrm{x}_{\mathrm{i}}$ represent independent parameters and $\varepsilon$ denotes error individually. Adsorption efficiency of soil recorded was evaluated with a standard RSM design [Central Composite Design (CCD)]. Twenty experiments recommended by the RSM scheme have been described in Table 2. These experiments were repeated thrice.

\section{Column studies}

The soil composites were taken in a porcelain sample port $(5 \mathrm{~cm}$ in length with a diameter of $10 \mathrm{~cm}$ ) and were saturated with distilled water. The flocculation of the composite membrane due to exposure to phenol was prevented by placing gravel particles above the sample bed. The solution passing through the membrane was collected in a Perspex chamber placed below the sample bed. The adsorbent membrane was carefully prepared for avoiding air gaps or cracks. The membrane permeates were sampled from the Perspex chamber at regular time intervals up to $150 \mathrm{~h}$. The concentration of residual phenol in the permeates were measured using a UV-VIS spectrophotometer (Model Hitachi-2800, Japan) by the process similar to batch studies [24].

\begin{tabular}{|c|c|c|c|c|c|c|}
\hline \multirow{2}{*}{ Parameters } & \multirow{2}{*}{ Unit } & \multicolumn{5}{|c|}{ Range and levels (coded) } \\
\cline { 3 - 7 } & & $-\alpha$ & -1 & 0 & +1 & $+\alpha$ \\
\hline $\mathrm{pH}$ & 2.9 & 4.0 & 5.5 & 7.0 & 8.0 \\
\hline $\begin{array}{c}\text { Adsorbent } \\
\text { Dose }\end{array}$ & $\mathrm{g} \mathrm{L}^{-1}$ & 3.3 & 5.0 & 7.5 & 10 & 11.7 \\
\hline Time & mins & 27.44 & 30 & 33.75 & 37.5 & 40.06 \\
\hline
\end{tabular}

Table 1: Experimental range and levels of independent parameters for RSM study.

\begin{tabular}{|c|c|c|c|c|}
\hline \multirow{2}{*}{$\begin{array}{c}\text { Experiment } \\
\text { no. }\end{array}$} & \multicolumn{3}{|c|}{ Parameters } & \multirow{2}{*}{$\begin{array}{c}\text { Adsorption } \\
\text { Capacity }\left(\mathrm{mg} \mathrm{g}^{-1}\right)\end{array}$} \\
\hline & pH & Adsorbent Dose $\left(\mathrm{g} \mathrm{L}^{-1}\right)$ & Time (in mins) & \\
\hline 1 & 7 & 5 & 37.5 & 1.001 \\
\hline 2 & 4 & 10 & 30 & 1.064 \\
\hline 3 & 4 & 5 & 37.5 & 1.034 \\
\hline 4 & 5.5 & 7.5 & 33.75 & 1.068 \\
\hline 5 & 5.5 & 7.5 & 33.75 & 1.004 \\
\hline 6 & 4 & 10 & 37.5 & 1.068 \\
\hline 7 & 5.5 & 11.7 & 33.75 & 1.004 \\
\hline 8 & 2.98 & 7.5 & 33.75 & 1.068 \\
\hline 9 & 7 & 10 & 37.5 & 1.004 \\
\hline 10 & 5.5 & 3.3 & 33.75 & 1.018 \\
\hline 11 & 5.5 & 7.5 & 33.75 & 1.028 \\
\hline 12 & 5.5 & 7.5 & 40.06 & 1.048 \\
\hline 13 & 7 & 10 & 30 & 1.068 \\
\hline 14 & 5.5 & 7.5 & 33.75 & 1.015 \\
\hline 15 & 5.5 & 7.5 & 27.44 & 1.068 \\
\hline 16 & 4 & 5 & 30 & 1.068 \\
\hline 17 & 8.02 & 7.5 & 33.75 & 1.000 \\
\hline 18 & 5.5 & 7.5 & 33.75 & 1.072 \\
\hline 19 & 5.5 & 7.5 & 33.75 & 1.068 \\
\hline 20 & 7 & 5 & 30 & 1.021 \\
\hline
\end{tabular}

Table 2: Central composite design (CCD) for optimization of three independent experimental factors guiding phenol adsorption onto soil along with the results obtained. 


\section{Characterization of adsorbent}

The soil (prior and post adsorption) was characterized by Fourier Transform Infrared Spectroscopy (FTIR) and Scanning Electron Microscopy (SEM) as described previously [17].

FTIR analysis of soil was recorded through the $\mathrm{KBr}$ pellet method with a resolution of $4 \mathrm{~cm}^{-1}$ using a Jasco FTIR-6300 Fourier Transform Infrared Spectrometer (JASCO, Japan) configured in transmittance mode.

Changes in the surface morphology of soil particles occurring due to adsorption was determined by a Scanning electron microscope (SEM) (ZEISS EVO-MA 10, Germany). Prior to analysis, the samples were subjected to gold coating in a sputter coater in lieu of increasing their conductivity for better visualization.

\section{Calculations}

Determination of equilibrium concentration and percent removal of phenol: The quantity of phenol adsorption at equilibrium $q_{e}\left(\mathrm{mg} \mathrm{g}^{-1}\right)$ was calculated from the mass balance equation given as follows:

$$
q_{e}=\frac{\left(c_{i}-c_{e}\right) v}{m}
$$

Where, $C_{i}$ is the initial phenol concentration $\left(\mathrm{mg} \mathrm{L}^{-1}\right), C_{e}$ is the equilibrium concentration of phenol in solution $\left(\mathrm{mg} \mathrm{L}^{-1}\right), V$ is the volume of the adsorbate solution (L) and $m$ is the mass of the adsorbent (soil) (g) used.

The percentage removal (\%) of phenol was calculated using Equation (2):

$$
\text { Removal }(\%)=\frac{\left(c_{i}-c_{e}\right) v}{c_{i}} \times 100
$$

Adsorption kinetics: The kinetic parameters were investigated in order to predict the rate of adsorption rate and support the modeling of the process of phenol adsorption. For this purpose, pseudo-first-order $[25,26]$ and pseudo-second-order [26,27] models were investigated. The correlation coefficients $\left(\mathrm{R}^{2}\right)$ were determined for both the models to assess their applicability to the process of concern.

The linear form of Lagergren pseudo-first-order model is given as follows:

$$
\log \left(q_{e}-q_{t}\right)=\left[\log q_{e}-\frac{k_{1}}{2.303} t\right]
$$

Where $q_{e}$ and $q_{t}$ indicate the concentration of phenol adsorbed (mg $\left.\mathrm{g}^{-1}\right)$ at equilibrium and at any time $(t)$ respectively, $k_{1}\left(\mathrm{~min}^{-1}\right)$ being the pseudo-first order rate constant.

The pseudo-second order kinetic model was calculated using Equation (4):

$$
\frac{\mathrm{t}}{\mathrm{q}_{\mathrm{t}}}=\frac{1}{\mathrm{k}_{2} \mathrm{q}_{\mathrm{e}}^{2}}+\frac{\mathrm{t}}{\mathrm{q}_{\mathrm{e}}}
$$

Where, $k_{2}\left(\mathrm{~g} \mathrm{mg}^{-1} \mathrm{~min}^{-1}\right)$ represents the pseudo-second order rate constant.

Adsorption thermodynamics: The activation energy for phenol adsorption onto soil, $E_{a}$, was determined using the Arrhenius equation (Equation 6) [28]:

$$
\ln k=\ln A-\frac{E_{a}}{R T}
$$

Where, $k$ represents the kinetic constant, $A$ indicates the preexponential factor, $E_{a}$ denotes the activation energy $\left(\mathrm{J} \mathrm{mol}^{-1}\right), R(8.3124$ $\mathrm{J} \mathrm{mol}^{-1}$ ) and $T$ are the ideal gas constant and the absolute temperature $(\mathrm{K})$ at which the reaction occurs respectively. The values of $A$ and $E a$ applied in Eq. 6 are determined from the slope and intercept of the Arrhenius plot of $\ln k$ vs $1 / T$ respectively.

Thermodynamic behavior of phenol adsorption on clayey soil were investigated in terms of variations in Gibbs free energy $\left(\Delta G^{\circ}\right)\left(\mathrm{kJ} \mathrm{mol}^{-1}\right)$ along with values of enthalpy $\left(\Delta H^{\circ}\right)\left(\mathrm{kJ} \mathrm{mol}^{-1}\right)$ and entropy $\left(\Delta S^{\circ}\right)(\mathrm{J}$ $\mathrm{mol}^{-1} \mathrm{~K}^{-1}$ ). These parameters were determined using the following equations [29]:

$$
K_{c}=\frac{c_{a}}{c_{e}}
$$

Where $\mathrm{K}_{\mathrm{c}}=$ coefficient of distribution for the adsorption; $\mathrm{C}_{\mathrm{a}}=$ Phenol adsorbed per unit mass of the adsorbent $\left(\mathrm{mg} \mathrm{L}^{-1}\right)$;

$$
\Delta G^{o}=-R T \ln K_{c}
$$

Where, $\mathrm{R}$ and $\mathrm{T}$ represented universal gas constant $\left(8.3124 \mathrm{~J} \mathrm{~mol}^{-1}\right)$ and absolute temperature $(\mathrm{K})$ respectively; and

$$
\Delta G^{o}=\Delta \mathrm{H}^{o}-\mathrm{T} \Delta S^{o}
$$

Measures of $\Delta H^{\circ}$ and $\Delta S^{\circ}$ were obtained from the slope and intercept of the linear plot of $\Delta G^{\circ}$ versus temperature (T) respectively.

Data analysis: All experiments were repeated thrice for ensuring the accuracy and reproducibility of the recorded data and expressed as mean values. Relative standard deviations evaluated varied within $\pm 2 \%$. Data were analyzed with Microsoft Excel 2007 program, USA and Origin (version 9.1; Origin Lab Corporation, USA).

\section{Results and Discussion}

\section{Effect of $\mathrm{pH}$}

The $\mathrm{pH}$ of the solution has an important effect on the process of phenol adsorption as the $\mathrm{pH}$ of the medium controls the magnitude of the electro-static charges that are imparted by ionized phenol molecules. As a result the rate of adsorption varies with the $\mathrm{pH}$ of an aqueous medium. Figure 1A shows the effect of $\mathrm{pH}$ on the removal efficiency of phenol exerted at different $\mathrm{pH}$ conditions ranging from 3-8. The maximum adsorption efficiency $\left(1.063 \mathrm{mg} \mathrm{g}^{-1}\right)$ was obtained at $\mathrm{pH}$ 5. However, adsorption efficiency showed a gradual decline with further rise in $\mathrm{pH}$. A decrease in the surface charge density of the adsorbent at higher $\mathrm{pH}$ values may have resulted in an electrostatic repulsion of the phenol molecules as reported previously [30].

\section{Effect of adsorbent dose}

The effect of adsorbent dosage on the removal of phenol is shown in the Figure 1B. The percentage of the phenol removal was seen to increase with a corresponding increase in adsorbent dose upto a certain limit beyond which the percentage removal decreased with an increase in the adsorbent dosage. The positive correlation between adsorbent dose and phenol removal may be related to an increase in the adsorbent surface area and availability of more adsorption sites as reported in previous studies [29]. Furthermore it was seen that beyond a dosage of $12.5 \mathrm{~g} \mathrm{~L}^{-1}$, a decreasing trend was observed which might have resulted from the absence of adsorption sites due to aggregation of adsorbent particles [31]. 

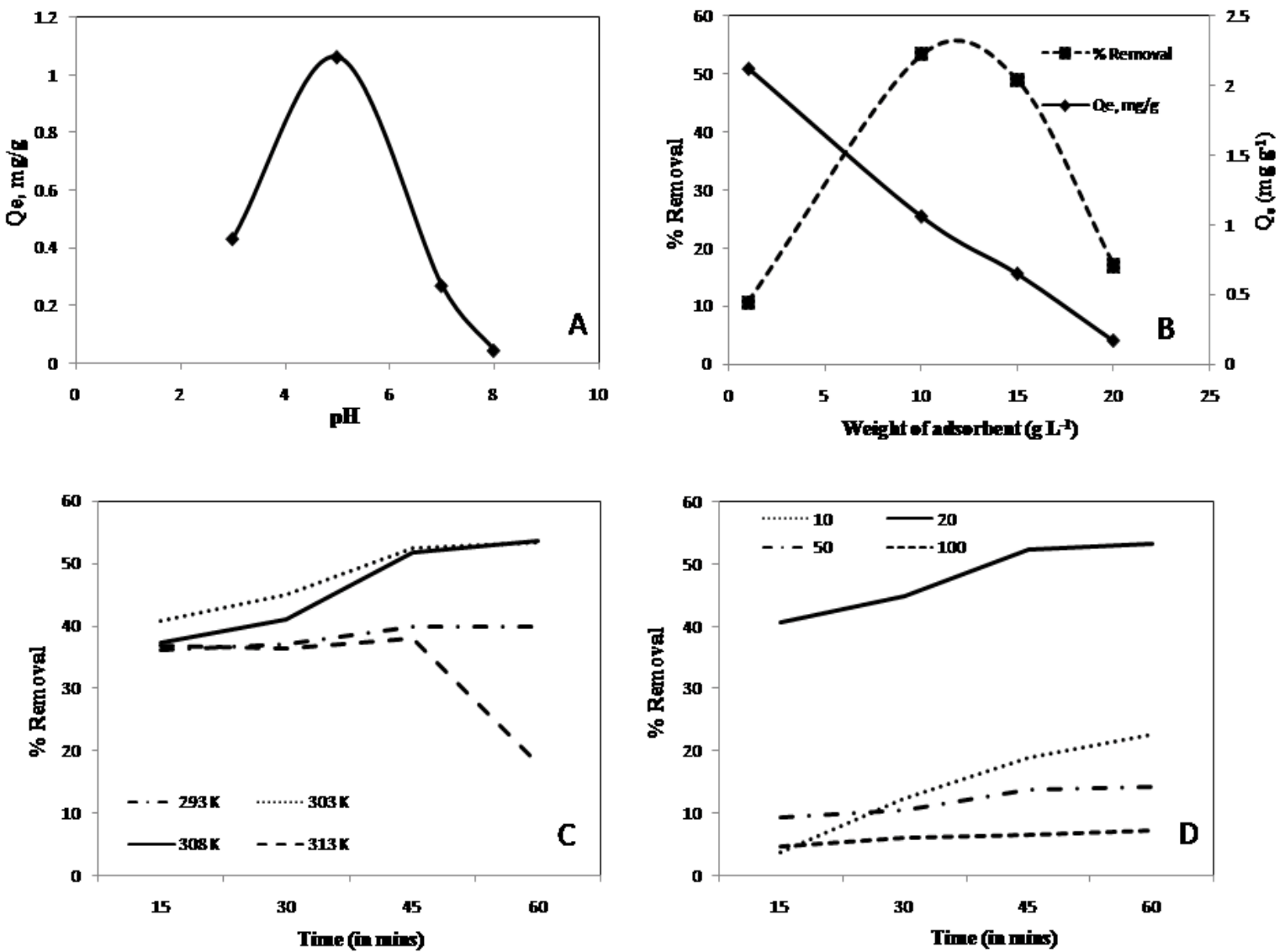

Figure 1: Graph showing effects of different experimental conditions on phenol adsorption capacity of soil. A: Effect of initial solution pH; B: Effect of adsorbent dosage; C: Effect of temperature; D: Effect of initial adsorbate concentration.

\section{Effect of temperature}

Temperature determines whether a process is exothermic or endothermic in nature. It has been previously reported that increase in the adsorption efficiency of an adsorbent with a corresponding increase in temperature indicates that the process is endothermic in nature [32]. The effect of temperature on the \% removal of phenol was studied in the temperature range of $293-313 \mathrm{~K}$ and the resultant phenol removal is shown in Figure 1C. The maximum adsorption efficiency (1.069 $\mathrm{mg} \mathrm{g}$ ) was obtained at $303 \mathrm{~K}$ beyond which a decrease in adsorption efficiency of soil with a corresponding rise in temperature was noted. The weakening of the adsorptive forces between the active sites on the adsorbent and the phenol species, and also between adjacent phenol molecules on the adsorbed phase may be considered as a probable explanation of the observed phenomenon. An increase in temperature may have decreased the adsorptive forces between the phenol species and the active sites on the adsorbent surface and thereby resulted in a decrease in the adsorption efficiency [33].

\section{Effect of initial adsorbate concentration}

Figure 1D shows the effect of initial phenol concentration on the $\%$ removal of phenol for four different concentrations (10, 20, 50 and $100 \mathrm{mg} \mathrm{L}^{-1}$ ) at $303 \mathrm{~K}$ and $\mathrm{pH}$ 5. The results indicated a decrease in the amount of phenol adsorbed with a consequent increase in initial phenol concentration. This may have occurred due to the saturation of the available active sites of the adsorbent beyond a certain concentration.
From the results it was evident that adsorption capacity of soil increased with a subsequent increase of initial phenol concentration up to 25 ppm afar from which it decreased mainly due to the absence of active sites as reported in previous literature [34].

\section{Estimation of response surface for maximum phenol removal}

The results obtained from the twenty experiments recommended by CCD are enlisted in Table 2. Results denote that on treating a phenol solution of concentration $25 \mathrm{mg} \mathrm{L}^{-1}$ will clay soil at $303 \mathrm{~K}$, maximum adsorption efficiency (1.068 $\mathrm{mg} \mathrm{g}^{-1}$ ) was achieved using $7.5 \mathrm{~g} \mathrm{~L}^{-1}$ of adsorbent at pH 5.5 after 32.5 mins of treatment.

An empirical relationship developed amidst the response and the independent parameters has been expressed by the quadratic equation given as follows:

Response $(\mathrm{R} 1)=-0.16013+0.12650^{*} \mathrm{pH}+0.61298^{*}$

Adsorbent dose +0.038016 * Time

$-0.010143^{\star} \mathrm{pH}^{2}-2.29080 \mathrm{E}-003^{\star}$ Adsorbent

dose $^{2}-3.73946 \mathrm{E}-004^{*}$ Time $^{2}+1.00000 \mathrm{E}-004$

* $\mathrm{pH}^{\star}$ Adsorbent dose $-6.44444 \mathrm{E}-004^{\star} \mathrm{pH}$

* Time -9.20000E-004*Adsorbent dose* Time (9)

The statistical significance of the model was tested by analyzing the model equation using F-test ANOVA. Significance of each coefficient 
Citation: Das P, Goswami S, Banerjee P, Datta S (2015) Phenol Adsorption onto Various Soil Composite Membranes: Insight into Process Kinetics, Modelling and Optimisation Using Response Surface Methodology. Hydrol Current Res 6: 203. doi:10.4172/2157-7587.1000203

was determined according to their F-values and P-values. A Fisher's F-value of 6.88 along with a low probability value $(\mathrm{P}<0.05)$ denoted a highly significant regression model incurring only a $0.29 \%$ chance this large "Model F-value" had resulted by chance. Additionally, multiple correlation coefficient $\left(\mathrm{R}^{2}\right)$ analysis was also carried out to determine the goodness of fit of this model. An $\mathrm{R}^{2}$ value of 0.861 rendered this regression model as statistically significant. The value of lack of fit was insignificant $(>0.05)$ thereby confirming the quadratic model appropriate for this study [35].

\section{Effect of variation in adsorbent dosage and time}

The concomitant effect of adsorbent dosage and time on adsorption of phenol has been shown in the 3D plot of Figure 2A. The residual phenol concentration was seen to decrease with a corresponding increase in adsorbent dose and contact time. This may have occurred due to an increase in adsorbent surface area bearing more adsorption sites $[29,31]$.

Effect of variation in initial solution $\mathrm{pH}$ and time: The synergistic effect of initial solution $\mathrm{pH}$ and time on adsorption of phenol has been shown in the 3D plot of Figure 2B. It is evident from the figure that $\%$ removal of phenol increased as both duration of treatment increased and initial solution $\mathrm{pH}$ decreased. This suggested that better values of phenol removal could be obtained by increasing both the time of contact and simultaneously decreasing the initial $\mathrm{pH}$ of the solution at the same time [17].
Effect of variation in initial solution $\mathbf{p H}$ and adsorbent dosage: The $3 \mathrm{D}$ plot of Figure 2C elucidates the mutual impacts of the independent variables (adsorbent dosage and $\mathrm{pH}$ ) on the process of phenol removal. According to this plot, adsorbent efficiency increased as initial solution $\mathrm{pH}$ decreased and adsorbent dosage increased simultaneously.

Adsorption isotherms: The Langmuir, Freundlich and Temkin models were selected in this study to evaluate the adsorption of phenol on Clay soil. The respective values of parameters and correlation coefficients are given in Table 3. The correlation factors and other parameters presented in Table 3 demonstrate high agreement between results obtained both theoretically and experimentally. The applicability of the isotherm equation to describe the adsorption process was judged by the correlation coefficient $\left(\mathrm{R}^{2}\right)$ value. For the Langmuir isotherm, the Ce/ qe vs Ce has been shown in Figure 3A. For the Freundlich isotherm, the plot of $\log$ Ce verses log qe has been shown in Figure 3B. A plot of qe verses $\ln \mathrm{Ce}$ for the Temkin isotherm has been shown in Figure 3C. The highest values of correlation coefficients were obtained for Temkin isotherm (0.999-1.000) indicating a monolayer coverage of the adsorbate (phenol) on the outer surface of the adsorbent [36]. The Temkin isotherm also explains the adsorbent-adsorbate interaction by predicting the linear decrease in the heat of adsorption (function of temperature) of all adsorbent molecules with time [36].

Adsorption kinetics: Investigation of adsorption kinetics yielded that the system reached equilibrium after $60 \mathrm{~min}$. The rate constants

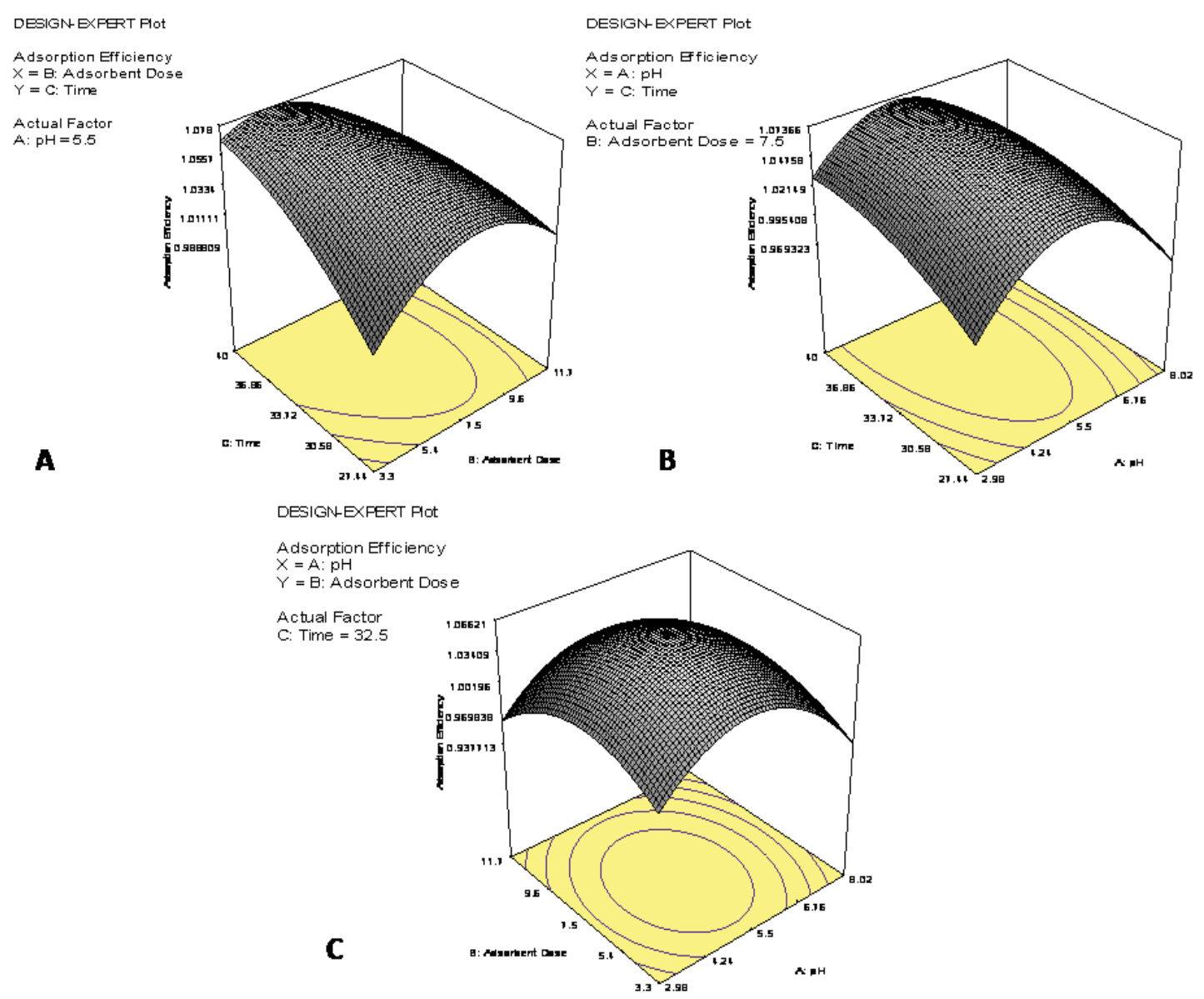

Figure 2: 3D plots showing effect of independent variables on percent removal of phenol. $\mathrm{A}$ : adsorbent dosage vs. time; $\mathrm{B}$ : $\mathrm{pH}$ vs. time; $\mathrm{C}$ : $\mathrm{pH}$ vs. adsorbent dosage. 
Citation: Das P, Goswami S, Banerjee P, Datta S (2015) Phenol Adsorption onto Various Soil Composite Membranes: Insight into Process Kinetics, Modelling and Optimisation Using Response Surface Methodology. Hydrol Current Res 6: 203. doi:10.4172/2157-7587.1000203

Page 6 of 10

\begin{tabular}{|c|c|c|c|c|c|}
\hline \multirow{2}{*}{ Models } & \multirow{2}{*}{ Parameters } & \multicolumn{4}{|c|}{ Temperature (K) } \\
\hline & & 298 & 303 & 308 & 313 \\
\hline \multirow{4}{*}{$\begin{array}{l}\text { Langmuir } \\
\frac{c_{e}}{q_{e}}=\frac{1}{Q^{o} b}+\frac{c_{e}}{Q^{o}}\end{array}$} & $C_{e}\left(\mathrm{mg} \mathrm{L}^{-1}\right)$ & 12.00 & 9.31 & 9.25 & 12.37 \\
\hline & $q_{e}\left(\mathrm{mg} \mathrm{g}^{-1}\right)$ & 0.79 & 1.06 & 1.07 & 0.76 \\
\hline & $b\left(\mathrm{~L} \mathrm{mg}^{-1}\right)$ & 0.13 & 0.18 & 0.17 & 0.10 \\
\hline & $\mathrm{R}^{2}$ & 0.999 & 0.996 & 0.995 & 0.998 \\
\hline \multirow{3}{*}{$\begin{array}{l}\text { Freundlich } \\
=\mathrm{InK}_{\mathrm{F}}+\frac{1}{\mathrm{n}_{\mathrm{f}}} \mathrm{InC}_{\mathrm{e}}\end{array}$} & $K_{F}\left(\mathrm{~L} \mathrm{mg}^{-1}\right)$ & 45.27 & 12.847 & 15.27 & 750.19 \\
\hline & $n_{f}$ & 0.61 & 0.90 & 0.84 & 0.36 \\
\hline & $\mathrm{R}^{2}$ & 0.999 & 0.997 & 0.996 & 0.999 \\
\hline \multirow{3}{*}{$\begin{array}{c}\text { Temkin } \\
\mathrm{q}_{e}=\mathrm{B}_{\mathrm{T}} \operatorname{InK}_{\mathrm{T}}+\mathrm{B}_{\mathrm{T}} \operatorname{InC}_{e}\end{array}$} & $K_{T}\left(\mathrm{~L} \mathrm{mg}^{-1}\right)$ & 22.84 & 25.77 & 25.03 & 21.01 \\
\hline & $B_{T}\left(\mathrm{~J} \mathrm{~mol}^{-1}\right)$ & 1.23 & 1.05 & 1.08 & 1.44 \\
\hline & $\mathrm{R}^{2}$ & 1.000 & 0.999 & 0.999 & 0.999 \\
\hline
\end{tabular}

Table 3: Comparative analysis of the isotherm parameters for adsorption of phenol onto soil.

for adsorption of phenol onto soil at different temperatures were calculated using Lagergren pseudo-first order and pseudo-second order kinetic models. The adsorption rate constant, $\mathrm{k}_{1}$ and $\mathrm{k}_{2}$ at different temperatures were calculated from the linear plots of $\log \left(\mathrm{q}_{\mathrm{e}}-\mathrm{q}_{\mathrm{t}}\right)$ vs. $\mathrm{t}$ (Figure not shown) and $t / q_{t}$ vs. $t$ (Figure 4$)$ respectively and are listed in Table 4 . The high values of regression correlation coefficients $\left(\mathrm{R}^{2}\right)$ and a good accord between the calculated and experimental $\mathrm{q}_{\mathrm{e}}$ values for pseudo-second order model shown in Table 4 denote that the adsorption of phenol onto soil is guided by the pseudo-second order rate kinetics. From the second order model it can be suggested that the overall rate of adsorption process was controlled by the chemisorptions which involved valency forces through sharing of exchange of electrons between the adsorbent and adsorbate moieties [37].

Using the values of pseudo-second-order rate constant $\mathrm{k}_{2}$ obtained at different temperatures, the activation energy Ea was derived using the Arrhenius equation. From the linear plot of $\ln k_{2}$ vs $1 / T$ (Figure not shown), activation energy for phenol adsorption was calculated to be $126.89 \mathrm{~kJ} \mathrm{~mol}^{-1}$, which on being much higher than $40 \mathrm{~kJ} \mathrm{~mol}^{-1}$ denoted that the adsorption phenomenon was a chemical reaction in nature. Also, corresponding rise in adsorption capacity with increase in temperature rendered the process as endothermic in nature.

Adsorption thermodynamics: Data obtained from batch studies revealed that $\Delta \mathrm{G}^{\circ}$ increased from $\left(-2.579 \mathrm{~kJ} \mathrm{~mol}^{-1}\right.$ to $-3.779 \mathrm{~kJ} \mathrm{~mol}^{-1}$ as a result of a corresponding ascend in the temperature (203-313 K). The negative $\Delta \mathrm{G}^{\circ}$ values recorded at all temperatures suggested the adsorption process to be a spontaneous phenomenon. Additionally, the positive value of enthalpy $\left(245.68 \mathrm{~kJ} \mathrm{~mol}^{-1}\right)$ obtained indicated the endothermic nature of the concerned process as it had occurred by utilization of energy from the system in concern. As the calculated heat of adsorption exceeded $80 \mathrm{KJ} \mathrm{mole}^{-1}$, the adsorption of phenol
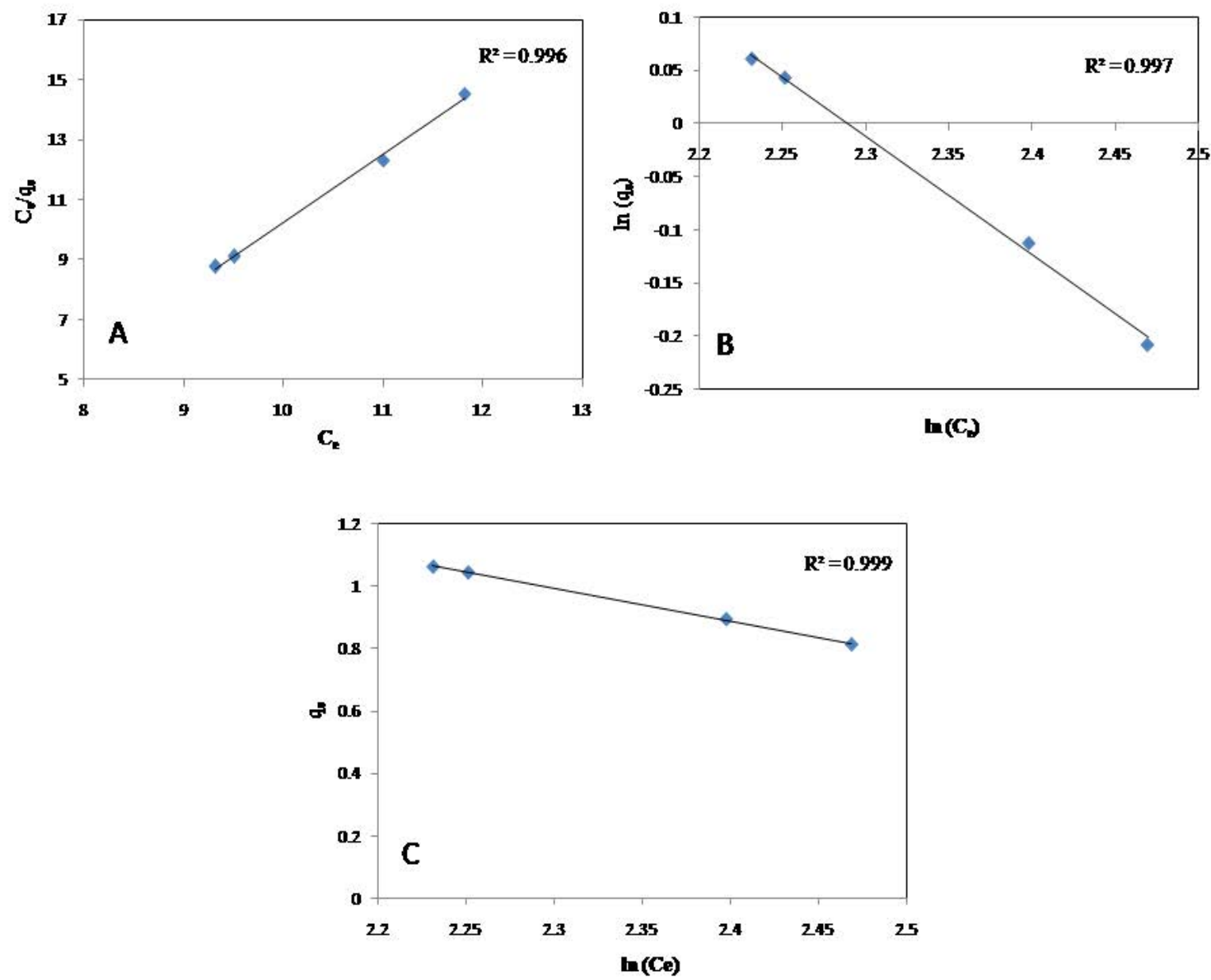

Figure 3: Graphs showing adsorption isotherm models. a) Langmuir isotherm plots for the adsorption of phenol onto soil; b) Freundlich isotherm plots for the adsorption of phenol onto soil; c) Tempkin isotherm plots for the adsorption of phenol onto soil. 
Citation: Das P, Goswami S, Banerjee P, Datta S (2015) Phenol Adsorption onto Various Soil Composite Membranes: Insight into Process Kinetics, Modelling and Optimisation Using Response Surface Methodology. Hydrol Current Res 6: 203. doi:10.4172/2157-7587.1000203

Page 7 of 10

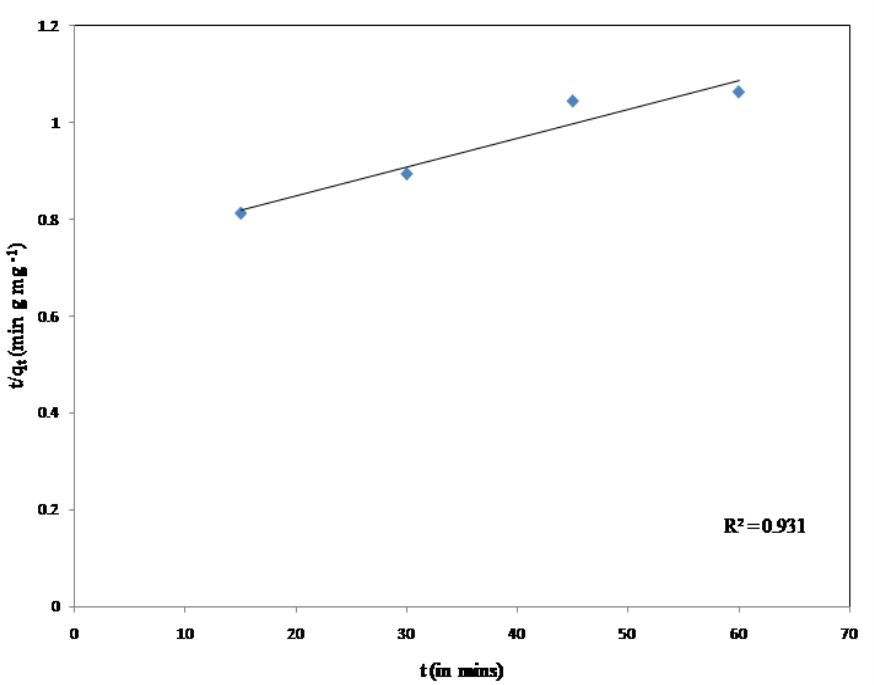

Figure 4: Graphs showing $t / q_{t}$ vs $t$ plot for pseudo second order kinetics at $303 \mathrm{~K}$.

\begin{tabular}{|c|c|c|c|c|c|}
\hline \multirow{2}{*}{ Models } & \multirow{2}{*}{ Parameters } & \multicolumn{4}{|c|}{ Temperatures (K) } \\
\hline & & 293 & 303 & 308 & 313 \\
\hline & $\mathrm{k}_{1}\left(\mathrm{~min}^{-1}\right)$ & 0.002 & 0.005 & 0.007 & 0.005 \\
\hline $\log \left(\mathrm{q}_{e}-\mathrm{q}_{\mathrm{t}}\right)=$ & $q_{e}($ cal $)$ & 1.31 & 1.29 & 1.41 & 1.66 \\
\hline$\left[\log \mathrm{q}_{e}-\frac{\mathrm{K}_{1}}{2.303} \mathrm{t}\right]$ & $\mathrm{R}^{2}$ & 0.881 & 0.932 & 0.93 & 0.673 \\
\hline Pseudo second order & $\left(\begin{array}{c}\mathrm{k}_{2} \\
\left.\mathrm{mg} \mathrm{g}^{-1} \min ^{-1}\right)\end{array}\right.$ & 0.42 & 0.10 & 0.06 & 0.03 \\
\hline$\frac{\mathrm{t}}{\mathrm{q}_{\mathrm{t}}}=\frac{1}{\mathrm{k}_{2} q_{e}^{2}}+\frac{\mathrm{t}}{\mathrm{q}_{e}}$ & $\mathrm{q}_{\mathrm{e}}(\mathrm{cal})$ & 0.83 & 1.21 & 1.30 & 1.14 \\
\hline
\end{tabular}

Table 4: Kinetic parameters for the adsorption of phenol onto soil calculated at temperatures ranging from 293-313.

on GO was assumed to be chemisorption in nature. Also, positive value for entropy of the reaction $\left(91.454 \mathrm{~J} \mathrm{~mol}^{-1} \mathrm{~K}^{-1}\right.$ ) obtained from the experimental data suggested that an increase in the translational entropy of the displaced water molecules above that of phenol ions released probably resulted in an increase in the randomness at the solid/solution interface as well. Similar observations were reported in previous studies as well $[17,34]$.

\section{Adsorption characterization}

\section{SEM analysis}

The surface morphology of the clayey soil prior and post adsorption was analyzed using a Scanning Electron Microscope (SEM) and the images are given as Figure 5A and 5B. Figures show a prominent change in the surface texture of the adsorbent resulting from phenol adsorption. Magnifications of the images are present inset.

\section{FTIR analysis}

The FTIR spectra of soil (before and after adsorption) are shown in Figure 6. The soil spectrum (Figure 6A) exhibited distinct peaks at $870,1,087$ and $1,412 \mathrm{~cm}^{-1}$ which represent $\mathrm{CH} / \mathrm{NH}_{2}, \mathrm{CO} / \mathrm{CN}$ and $\mathrm{O}-\mathrm{H}$ bonds, respectively. Most of the peaks present in spectrum A (Figure 6) are increased or shifted in spectrum B (Figure 6), which denotes soil after adsorption. The enlarged or shifted peaks might have been formed as a result of chemical interactions occurring between phenol and functional groups of soil moieties. These observations are also supported by previous findings [17].

Column study: It is evident from Figure 7 that the \% removal of phenol varied with different soil composite materials and was highest in case of soil used solely. Results revealed that maximum adsorption efficiency (1.066 $\left.\mathrm{mg} \mathrm{g}^{-1}\right)$ was obtained when soil was applied with cement as a composite closely followed by soil used without modifications. Cement bound to soil particles thereby decreasing its porosity and restricted the passage of phenol moieties through the composite membrane [17]. In soil-lime composite, calcium ions present in lime affect the double diffuse layer of soil and thereby result in an increase in its porosity [38]. This increase in porosity in turn facilitates the passage of phenol moieties through this membrane. When bentonite was used to prepare a composite with soil, though an increase in the clay content of the adsorbent was observed, but transportation rate of phenol through this membrane was found to decrease owing to the shrinkage effect of bentonite. In case of soil-gypsum composite, presence of two contradictory properties (binding property and calcium ion effect) result in a reduction in \% removal of phenol when passed through the
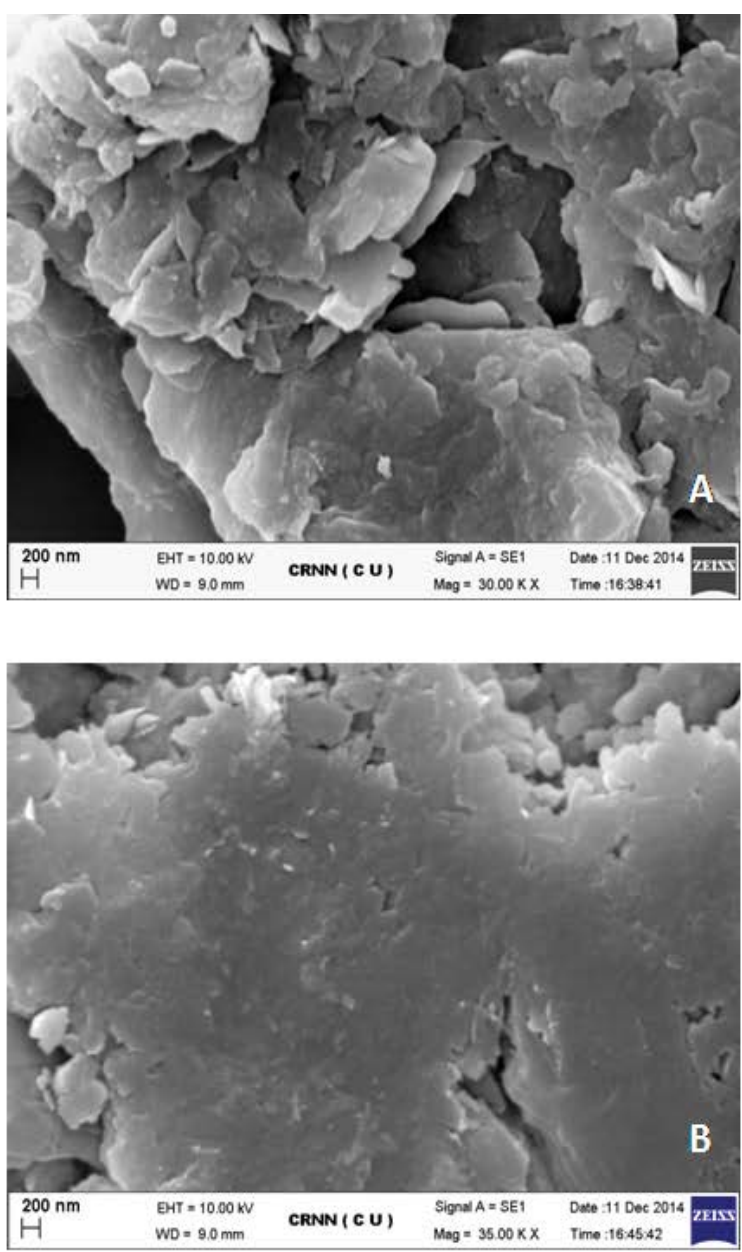

Figure 5: SEM images of soil. A and B denote soil taken before and after adsorption respectively. 


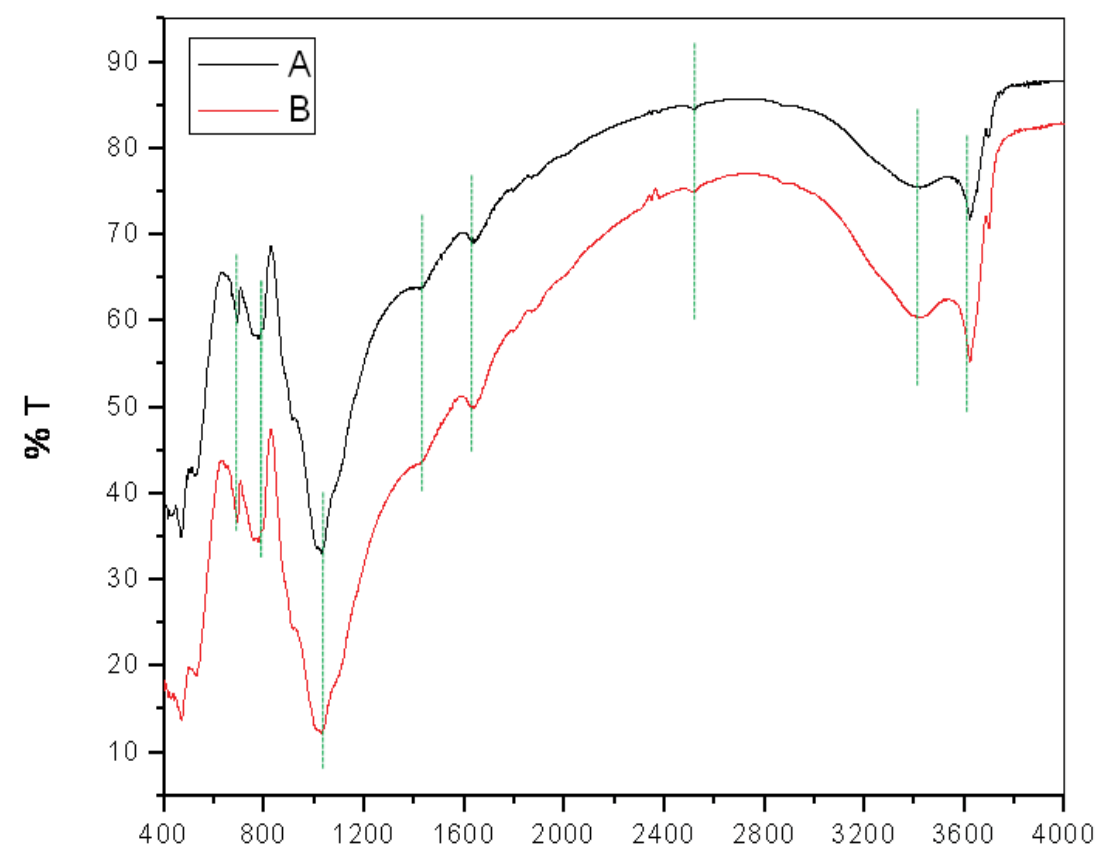

Figure 6: FTIR images of soil. Spectrum A indicates soil before adsorption of phenol; Spectrum B indicates soil before adsorption of phenol; dotted green lines indicate peak sizes before and phenol.

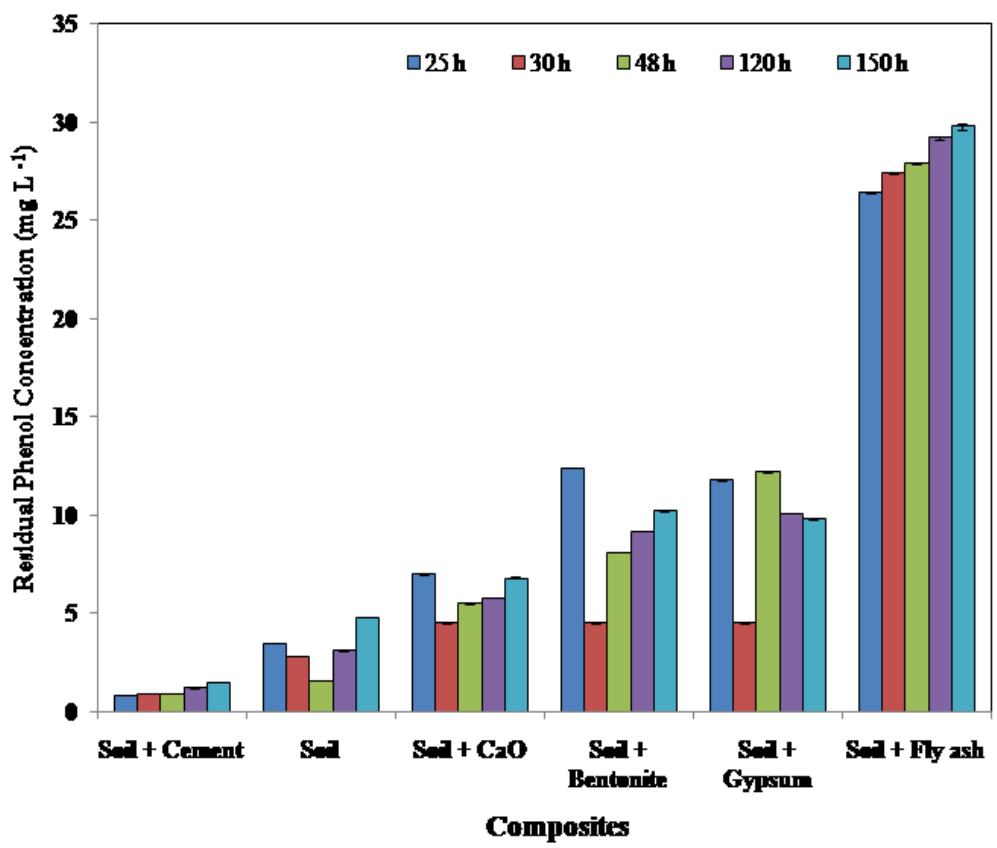

Figure 7: Graph showing residual phenol concentration $\left(\mathrm{mg} \mathrm{L}^{-1}\right)$ of phenol solution passing through the columns containing soil and different soil composites with respect to time.

soil-gypsum composite. Lowest adsorption capacity was exhibited by soil-flyash composite which indicated that the binding of soil-fly ash was not so good like soil-cement mixture. In all cases other than phenol solutions treated with soil-cement composite, the concentration of phenol passing through the different soil composite membranes was lower than the permissible limit.

\section{Conclusion}

The experimental results indicate that the soil and soil composites have the potential adsorption capacity for phenol removal. As predicted by the RSM design, a maximum adsorption efficiency of $1.44 \mathrm{mg} \mathrm{g}^{-1}$ was obtained when a phenol solution of $20 \mathrm{ppm}$ with initial $\mathrm{pH} 5.5$ 
Citation: Das P, Goswami S, Banerjee P, Datta S (2015) Phenol Adsorption onto Various Soil Composite Membranes: Insight into Process Kinetics, Modelling and Optimisation Using Response Surface Methodology. Hydrol Current Res 6: 203. doi:10.4172/2157-7587.1000203

was treated with an adsorbent dosage of $7.5 \mathrm{~g} \mathrm{~L}^{-1}$ for 32.5 mins at a temperature of $313 \mathrm{~K}$. Furthermore, the adsorption equilibrium data recorded at different temperatures best fitted the Temkin isotherm adsorption model very well. The process of adsorption was best guided by the pseudo second order kinetic model in comparison to the pseudo first order model. The adsorption process was found to be spontaneous, endothermic and chemisorptions in nature. Due to its wide availability, low cost, biodegradable and environmentally benign nature, soil and soil composites might be considered as an appropriate liner material for the treatment of wastewater rich in phenol and phenolic compounds.

\section{Acknowledgement}

Authors would like to acknowledge all members of Department of Chemical Engineering, Jadavpur University and Department of Environmental Science, University of Calcutta for their utmost cooperation and support throughout the study. Authors also acknowledge Mr. Tridip Sen Center for Research in Nano science and Nanotechnology for helping with SEM analysis.

\section{References}

1. Ahmaruzzaman Md (2008) Adsorption of phenolic compounds on low-cost adsorbents: a review. Advances in Colloid and Interface Science 143: 48-67.

2. Ispas CR, Ravalli MT, Steere A, Andreescu S (2010) Multifunctional bio magnetic capsules for easy removal of phenol. Water Research 44: 1961-1969.

3. Ahmaruzzaman Md, Gayatri SL (2011) Activated neem leaf: a novel adsorbent for the removal of phenol, 4-nitrophenol, and 4-chlorophenol from aqueous solutions. Journal of Chemical and Engineering Data 56: 3004-3016.

4. Patterson JW (1997) Wastewater Treatment Technology, Ann Arbor Science, Ann Arbor, MI.

5. Moyo M, Mutare E, Chigondo F, Nyamunda BC (2012) Removal of phenol from aqueous solution by adsorption on yeast, Saccharomyces cerevisiae. International Journal of Research and Reviews in Applied Science 11: 486-494.

6. Girods P, Dufour A, Fierro V, Rogaume Y, Rogaume C, et al. (2009) Activated carbons prepared from wood particleboard wastes characterization and phenol adsorption capacities. Journal of Hazardous Materials 166: 491-501.

7. Koumanova B, Peeva P, Allen SJ, Gallagher KA, Healy MG (2002) Bio adsorption from aqueous solutions by eggshell membranes and Rhizopusoryzae: equilibrium and kinetic studies. Journal of Chemical Technology and Biotechnology 77: 539-545.

8. Kuh SE, Kim DS (2000) Removal characteristics of cadmium ion by waste eggshell. Environmental Technology 21: 883-890.

9. Pereira MFR (2006) Adsorption of a reactive dye on chemically modified activated carbons-influence of $\mathrm{pH}$. Journal of Colloid and Interface Science 296: $480-489$.

10. Calace N, Nardi E, Petronio BM, Pietroletti M (2002) Adsorption of phenols by paper mill sludge. Environment Pollution 118: 315-319.

11. Mahvi AH, Maleki A, Eslimi A (2004) Potential of rice husk ash for phenol removal in aqueous systems. American Journal of Applied Sciences 1: 321326.

12. Uddin MT, Islam MS, Abedin MZ (2007) Adsorption of phenol from aqueous solution by water hyacinth ash. Journal of Engineering and Applied Sciences 2: 11-17.

13. Aravindhan R, Rao JR, Nair BU (2009) Application of a chemically modified green macro alga as a biosorbent for phenol removal. Journal of Environmental Management 90: 1877-83.

14. Stadelman WJ (2000) Eggs and egg products. In: Francis FJ (ed) Encyclopedia of Food Science and Technology, (2ndedn) John Wiley \& Sons, New York. pp. 593-599.

15. Batzias FA, Sidiras DK (2004) Dye adsorption by calcium chloride treated beech sawdust in batch and fixed-bed systems. Journal of Hazardous Materials 114: $167-174$.

16. Chojnacka K (2005) Biosorption of $\mathrm{Cr}(\mathrm{III})$ ions by eggshells. Journal of Hazardous Materials 121: 167-173.
17. Das $P$, Banerjee $P$, Mondal S (2014) Mathematical modelling and optimization of synthetic textile dye removal using soil composites as highly competent liner material. Environmental Science and Pollution Research 22: 1318-1328.

18. Hamsaveni DR, Prapulla SG, Divakar S (2001) Response surface methodological approach for the synthesis of isobutyl butyrate. Process Biochemistry 36: 1103-1109.

19. Amini M, Younesi H, Bahramifar N, Lorestani AAZ, Ghorbani F, et al (2008) Application of response surface methodology for optimization of lead biosorption in an aqueous solution by Aspergillus niger. Journal of Hazardous Materials 154: 6940-702.

20. Chowdhury S, Chakraborty S, Saha PD (2013) Response surface optimization of a dynamic dye adsorption process: a case study of crystal violet adsorption onto $\mathrm{NaOH}$-modified rice husk. Environmental Science and Pollution Research 20: $1698-1705$.

21. Jain M, Garg VK, Kadrivelu K (2011) Investigation of Cr (VI) adsorption onto chemically treated Helianthus annus: optimization using response surface methodology. Bioresource Technology 102: 600-605.

22. Satapathy MK, Das P (2014) Optimization of crystal violet dye removal using novel soil-silver nanocomposite as nanoadsorbent using response surface methodology. Journal of Environmental Chemical Engineering 2: 708-714.

23. Jaman $H$, Chakraborty D, Saha $P$ (2009) A study of the thermodynamics and kinetics of copper adsorption using chemically modified rice husk. Clean-Soil Air Water 37: 704-711.

24. Torralba EA, Rubio A'M, Guardia M (2005) Determination of phenols in waters using micro-pumped multi commutation and spectrophotometric detection: an automated alternative to the standard procedure. Analytical and Bioanalytical Chemistry 383: 138-144.

25. Lagergren $S$ (1898) About the theory of so-called adsorption of soluble substances. Kungliga Svenska Vetenskapsakademiens Handlingar 24: 1-39.

26. Saha P, Chowdhury S, Gupta S, Kuma I (2010) Insight into adsorption equilibrium, kinetics and thermodynamics of malachite green onto clayey soil of Indian origin. Chemical Engineering Journal 165: 874-882.

27. Ho YS, McKay G (1999) Pseudo-second-order model for sorption processes. Process Biochemistry 34: 451-465.

28. Anirudhan TS, Radhakrishnan PG (2008) Thermodynamics and kinetics of adsorption of $\mathrm{Cu}$ (II) from aqueous solutions onto a new cation exchanger derived from tamarind fruit shell. The Journal of Chemical Thermodynamics 40: 702-709.

29. Saeed A, Sharif M, Iqbal M (2010) Application potential of grapefruit peel as dye sorbent: Kinetics, equilibrium and mechanism of crystal violet adsorption. Journal of Hazardous Materials 179: 564-572.

30. Alshabanat M, Alsenani G, Almufarij R (2013) Removal of crystal violet dye from aqueous solutions onto date palm fiber by adsorption technique. Journal of Chemistry.

31. Aksakal O, Ucun H (2010) Equilibrium, kinetic and thermodynamic studies of the biosorption of textile dye (Reactive Red 195) onto Pinus sylvestris L. Journal of Hazardous Materials 181: 666-672.

32. Senthilkumaar S, Kalaamani P, Porkodi K, Varadarajan PR, Subburaam CV (2006) Adsorption of dissolved reactive red dye from aqueous phase on to activated carbon prepared from agricultural waste. Bioresource Technology 97 : 1618-1625.

33. Ofomaja AE, Ho YS (2007) Effect of $\mathrm{pH}$ on cadmium biosorption by coconut copra meal. Journal of Hazardous Materials 139: 356-362.

34. Satapathy MK, Banerjee P, Das P (2013) Plant-mediated synthesis of silvernanocomposite as novel effective azo dye adsorbent. Applied Nanoscience 5 $1-9$.

35. Amini M, Younesi H, Bahramifar N, Lorestani AAZ, Ghorbani F, Danesh A, Sharifzadeh M (2008) Application of response surface methodology for optimization of lead biosorption in an aqueous solution by Aspergillus niger Journal of Hazardous Materials 154: 694-702.

36. Khan TA, Ali I, Singh VV, Sharma S (2009) Utilization of fly ash as low-cost adsorbent for the removal of methylene blue, malachite green and rhodamine b dyes from textile wastewater. Journal of Environmental Protection 3: 11-22.

37. Dada AO, Olalekan AP, Olatunya AM, Dada O (2012) Langmuir, Freundlich, 
Citation: Das P, Goswami S, Banerjee P, Datta S (2015) Phenol Adsorption onto Various Soil Composite Membranes: Insight into Process Kinetics, Modelling and Optimisation Using Response Surface Methodology. Hydrol Current Res 6: 203. doi:10.4172/2157-7587.1000203

Page 10 of 10

Temkin and Dubinin-Radush kevich isotherms studies of equilibrium sorption of $\mathrm{Zn}^{2+}$ unto phosphoric acid modified rice husk. IOSR Journal of Applied Chemistry 3: $38-45$.
38. Saha P, Sanyal SK (2010) Assessment of the removal of cadmium present in wastewater using soil-admixture membrane. Desalination 259: 131-139. 